\title{
Can18F-FDG PET/CT overcome endoscopy in the staging of gastrointestinal involvement in Mantle Cell Lymphoma? A retrospective multi-center cohort analysis.
}

Tetiana Skrypets ( $\nabla$ tetianaskrypets@gmail.com )

Universita degli Studi di Modena e Reggio Emilia https://orcid.org/0000-0002-2276-869X

\section{Luca Nassi}

Azienda Ospedaliero-Universitaria Maggiore della Carita

Gloria Margiotta Casaluci

Azienda Ospedaliero-Universitaria Maggiore della Carita

Benedetta Puccini

Azienda Ospedaliero Universitaria Careggi

Lara Mannelli

Azienda Ospedaliero Universitaria Careggi

Sofya Kovalchuk

Azienda Ospedaliero Universitaria Careggi

Kateryna Filonenko

National Cancer Institute

Irina Kryachok

National Cancer Institute

Angela Monica Sciacovelli

IRCCS Istituto Tumori Giovanni Paolo II

Maria Carmela Vegliante

IRCCS Istituto Tumori Giovanni Paolo II

Antonella Daniele

IRCCS Istituto Tumori Giovanni Paolo II

Gianmauro Sacchetti

Azienda Ospedaliero-Universitaria Maggiore della Carita

Cristina Ferrari

D.I.M.-Diagnostic Imaging-Nuclear Medicine, University of Bari "Aldo Moro"

Attilio Guarini

IRCCS Istituto Tumori Giovanni Paolo II

Carla Minoia

IRCCS Istituto Tumori Giovanni Paolo II 


\section{Research article}

Keywords: Mantle Cell Lymphoma, extranodal, gastric involvement, colorectal involvement, 18F-FDG $\mathrm{PET} / \mathrm{CT}$

Posted Date: January 28th, 2020

DOI: https://doi.org/10.21203/rs.2.22047/v1

License: (c) (1) This work is licensed under a Creative Commons Attribution 4.0 International License. Read Full License 


\section{Abstract}

Background. Mantle-cell lymphoma (MCL) represents the $5-7 \%$ of all lymphoid malignancies. In $15-30 \%$ of cases by different data, MCL may affect the gastrointestinal tract (GI), but the real frequency by endoscopy and imaging could be significantly higher. Actually, by guidelines there are no recommendations for GI endoscopy in every patient with MCL. Therefore, we conducted the present multicenter study with the aim to evaluate the performance of the 18F-FDG PET/CT in the detection of GI involvement in patients with MCL and establish whether it is possible to omit endoscopy.

Methods. We retrospectively evaluated 79 patients with newly diagnosed $\mathrm{MCL}$, who had performed a pretreatment 18F-FDG PET/CT scan and GI endoscopy with biopsy.

Results. By PET/CT, overall GI tract involvement was found in $24 \%$ of patients. The performance of PET/CT have been evaluated by sensitivity, specificity, positive predictive value, negative predictive value and accuracy in the upper and lower GI tract. Using Cohen's k test, PET/CT and EGD with biopsy showed a fair agreement $(0.20,66.6 \%)$. However, PET/CT and colorectal biopsy showed a moderate agreement $(0.49,76 \%)$.

Conclusion. Analyzed data suggest that the performance of 18F-FDG PET/CT is not excellent in the detection of gastric lesions by MCL, and thus EGD with biopsy has yet to be considered a "golden standard" in this subset, while colonoscopy could be omitted due to a higher accuracy and specificity. Taking into account the limit of the retrospective nature of the study, data should be confirmed on larger and prospective cohort.

\section{Introduction}

Mantle-cell lymphoma (MCL) is a B-cell non-Hodgkin lymphoma (B-NHL) derived from a naïve pregerminal B-center cells in the mantle zone of secondary follicles and usually with aggressive course [1]. By different data, MCL represents $2-10 \%$ of all NHL with male predominance and median age at onset of about 60 years. Usually patients have an advanced stage disease, with almost $70 \%$ of them presenting a stage IV for bone marrow or extranodal involvement. Clinical prognostic factors are assessed by MCL International Prognostic Index (MIPI) $[2,3]$. Molecular pattern of $M C L$ is characterized by $t(11 ; 14)(q 13 ; q 32)$ translocation and cyclin D1 overexpression [4]. High Ki-67 rate (>30\%), TP53 mutation and complex karyotype usually match with more aggressive clinical behavior [5]. However, there is a subset of patients who have an indolent course, characterized by non-nodal disease, splenomegaly, peripheral blood spread, low Ki-67 rate (<10\%), SOX11-negative and IGHV mutated status [6].

Current guidelines recommend fluorine-18-fluorodeoxyglucose positron emission tomography (PET)/computed tomography (CT) (18F-FDG PET/CT) for staging and response to treatment assessment of FDG-avid lymphomas, in which MCL is included [7,8]. 18F-FDG PET/CT has showed a high accuracy rate in the detection of both nodal and extranodal involvement by FDG-avid lymphomas, becoming the golden standard imaging technique. The sensitivity of 18F-FDG PET/CT in the detection of nodal 
involvement of MCL at staging is $100 \%$ [9]. Principal sites of extranodal involvement by MCL are bone marrow (BM) and gastrointestinal (GI) tract. However, many other structures could be involved (rhinopharynx, orbit, central nervous system, etc). The sensitivity of 18F-FDG PET/CT for extranodal involvement has not been well established. By the last data by Albano et al., BM biopsy could not be replaced by 18 F-FDG PET/CT because of low sensitivity $52 \%$ and specificity $98 \%$ [10].

GI involvement is historically reported in about the $15-30 \%$ of patients, but hypothetically this percentage is underestimated, due to the execution of endoscopic exams just for symptomatic patients and to the lack of extensive endoscopy in trials on MCL. In analysis of prospective trials specifically designed to assess the $\mathrm{GI}$ tract also in asymptomatic patients (74\%), higher percentage of localization have been reported. In fact, if endoscopic biopsy had been performed, the positivity reached $43 \%$ in the upper and $88 \%$ in the lower GI tract. However, the authors conclude that the routinary execution of endoscopic exams had led to change the clinical stage and management only in $4 \%$ of patients [11]. Similar data have been obtained by Salar et al. in a little cohort of patients, who underwent prospectically endoscopic evaluation at baseline, demonstrating histological positivity in $77 \%$ of cases both in the upper and in the lower GI tract [12]. GI tract involvements in both studies were mostly asymptomatic and often affected many GI segments. Endoscopy results showed negativity or non-specific lesions in the stomach, which were characterized by micro-polyposis in the colon. Patients with normal or non-specific endoscopic findings can be positive at the histological examination, which has been intensively improved by molecular studies [12,13].

A limited number of published studies demonstrated a low sensitivity of 18F-FDG PET/CT for GI involvement [10]. The bottom line seems to be that gastric lesions could differ from each other, and to establish their exact nature is possible just after endoscopy with biopsy. In this field, there is still an open question: with the advent of more sophisticated 18F-FDG PET/CT scans, is it possible to diagnose GI involvement in patients with MCL just with 18F-FDG PET/CT? Nowadays, we have not clear data, whether $18 \mathrm{~F}-\mathrm{FDG} \mathrm{PET} / \mathrm{CT}$ is able to detect GI involvement and eventually guide or substitute the endoscopic exams.

Therefore, we conducted the present multi-center retrospective study, with the aim to: i) evaluate the accuracy of the 18F-FDG PET/CT in the detection of GI involvement in patients with MCL compared to GI endoscopy with biopsy, and ii) to establish whether it is possible to omit endoscopy.

\section{Patients And Methods}

\section{Study design}

From october 2006 to october 2019, we retrospectively included in the study consecutive patients diagnosed with MCL and treated at: Hematology Unit of IRCCS Istituto Tumori "Giovanni Paolo II", Bari, Italy; Haematology Department, Azienda Ospedaliero-Universitaria Maggiore della Carità, Novara, Italy; Haematology, University of Firenze, Firenze, Italy; Department of Oncohematology, National Cancer Institute, Kyiv, Ukraine. Inclusion criteria were: age $\geq 18$ years, histologically proven diagnosis of MCL 
according to the revised 2016 World Health Organization classification of lymphoid neoplasms [1], performed 18F-FDG PET/CT scan for staging. All patients provided written informed consent before enrollment into the study and were free to withdraw from the study at any time. This protocol was approved by the local ethical committees, in accordance with the principles of the Declaration of Helsinki and the Guidelines for Good Clinical Practice. No fundings have been received for the study. A detailed staging was performed, including medical history, physical examination, laboratory parameters, computed tomography, bone marrow biopsy, esophagogastroduodenoscopy (EGD) with biopsy and colonoscopy with biopsy. Cheson's revised criteria for malignant lymphoma were used to assess the stage [8]. Patients started chemotherapy immediately after the baseline examinations, with different regimens according to age and eligibility for high-dose chemotherapy.

The primary endpoint of the study was to assess the performance of the 18F-FDG-PET/CT in the detection of $\mathrm{Gl}$ involvement (gastric and colorectal). The secondary endpoint was to compare the $18 \mathrm{~F}$ FDG-PET/CT and endoscopic biopsies in order to establish whether to obmit endoscopic exams in the staging of MCL patients.

\section{F-FDG PET/CT protocol and comparison between 18F-FDG PET/CT and endoscopic GI exams}

According to 18F-FDG PET/CT guidelines, patient preparation includes fasting for at least $6 \mathrm{~h}$, adequate hydration, blood glucose measurement, an intravenous injection of a tracer whose dose depends on the tomograph and the patient's weight, and waited uptake time of 45-60 minutes. The PET/CT scanner was a Discovery PET/CT system (Bari: GE Healthcare - Milwaukee, WI USA; Novara: Siemens Biograph $16 \mathrm{Hi}$ Rez TN USA; Firenze: Siemens Biograph 16 Hi Rez; TN USA; Kyiv: Siemens Biograph 64, Germany). Supine decubitus under the scanner with arms in front of the pelvis is the position chosen for optimal image reading and interpretation and to avoid overlapping the arms with the spine. The fields of view includes from the skull to mid-thigh (5-7 bed positions). The Discovery system includes a multidetector helical CT scanner [14].

From the 18F-FDG PET/CT scan, we evidenced all the extranodal lymphoma's localization. We extrapolated the GI tract involvement, distinguishing gastric and colorectal ones. Both focal and diffuse captations were considered. True positive and false positive were then evaluated with GI biopsy.

\section{Statistical analysis}

A descriptive analysis was performed for sample description and frequencies.

The overall sensitivity (Se), specificity (Sp), positive predictive value (PPV), negative predictive value (NPV) and accuracy (Ac) of 18F-FDG PET/CT were calculated with $95 \%$ confidence intervals in relation to the 12-month clinical-instrumental follow-up period, taken as the standard of reference. PPV, NPV and accuracy were calculated dependently on prevalence of the event. PPV,NPP, specificity and sensitivity were calculated by means of MedCalc Software for Windows 
Cohen's K test was performed using R package "psych" within " R" statistical software v 3.6.1 and used to estimate the degree of agreement between 18F-FDG PET/CT and GI endoscopic and bioptic findings. By using an evaluation on a lesion-by-lesion basis, we calculated the overall agreement between the two methods in assessing GI involvement. Results interpretation had been defined as "slight agreement" 0.01-0.20; "fair agreement" - 0.21-0.40; "moderate agreement" - 0.41-0.60; "substantial agreement" - 0.610.80 ; "almost perfect or perfect agreement" - 0.81-1.00 [15].

\section{Results}

\section{Patients' characteristics}

We retrospectively enrolled a homogeneous cohort of 79 patients with a histologically proven MCL (6.3\% presenting a blastoid variant). Median age was 66.8 years (range, 27-83), 52 were men (65.8\%) and 27 women (34.2\%). The baseline characteristics are summarized in Table 1. The majority (n. 71, 89.9\%) presented an advanced stage disease (III/IV), with bone marrow infiltration (n. 58, 75.3\%). B-symptoms were reported in $8 \%$ at the onset of the disease. MIPI score was prevalently intermediate (n. $28,35.5 \%$ ) or high (n. 31, 39.2\%). Simplified MIPI showed similar results (intermediate risk 50.6\%, high risk 25.3\%). Ki67 evaluation was available in 48 lymph node biopsies (60.7\%) and was quite equally distributed as less (52\%) and more than $30 \%(48 \%)$.

All patients had been staged with 18F-FDG PET/CT, which allowed to identify several (n. 9, 11.4\%) extranodal localization of MCL other than bone marrow and GI. In our cohort, orbital (22.2\%) and liver (22.2\%) involvement were the most frequent extranodal sites of disease.

The majority of patients eligible for intensified therapy received R-CHOP (rituximab, cyclophosphamide, doxorubicin, vincristine, prednisone) alternated to R-DHAP (rituximab, dexamethasone, high-dose ara-C, cisplatin) or R-DHAOx (rituximab, dexamethasone, high-dose ara-C, oxaliplatin) (n. 16, 20.6\%), or R-CHOP and high-dose aracytin (n. 3,3.8\%), or R-BAC500 (rituximab, bendamustine, high-dose cytarabine) (n. 4, $5.1 \%) .21$ patients (14.1\%) underwent autologous hematopoietic stem cell transplant (ASCT). Patients not eligible for intensified chemotherapy received R-CHOP (n. 16, 20.6\%), R-BAC500 (n. 10, 12.8\%), Rbendamustine (n.22, 28.2\%) or R-CVP (rituximab, cyclophosphamide, prednisone) (n. 3, 3.8\%). The 14.1\% (n. 11) proceed with rituximab maintenance after induction chemotherapy. Finally, 4 patients $(5.1 \%)$ followed a "watch and wait" approach. The overall response rate to first line chemotherapy with or without ASCT consolidation (evaluable in 62 out of 70 patients) was $94.2 \%$ with a complete response for most patients (n. 51, 82.2\%), but relapses/progressions were frequently observed (52.3\%).

\section{GI endoscopic and pathologic findings}

In order to establish the performance of 18F-FDG PET/CT in the detection of GI extranodal involvement by $\mathrm{MCL}$, we identify patients who had been staged also with endoscopic exams. EGD had been done in $44(55.7 \%)$ and colonoscopy in $28(35.4 \%)$ patients. Gastric biopsy had been performed in 39 patients (49.4\%), colorectal biopsy in $25(31.6 \%)$. 
At staging, a positive EGD was found in 15 patients out of 44 (34\%). Gastric biopsy was positive for MCL localization in 13 patients (29.5\%). Chronic gastritis (1 Helicobacter pylori positive) was histologically documented in 4 cases $(9 \%)$.

A positive colonoscopy was reported in 9 patients (32.1\%) and was mainly characterized by micropoliposis. Colorectal biopsy was positive for MCL in 11 patients $(28.2 \%)$.

Only a minority of patients with positive endoscopic and bioptic exam at staging underwent EGD (n. 7 out of $44,15.9 \%$ ) and colonoscopy (n. 6 out of $39,21.4 \%$ ) at the end of treatment. Among endoscopic exams and biopsies performed at re-staging, only one patient in partial response presented a persistent colorectal positivity confirmed with biopsy.

\section{Correlation between 18F-FDG PET/CT and endoscopic biopsies}

By 18F-FDG PET/CT scan, we evaluated GI tract involvement in the different regions. Overall, we found a GI positivity in 19 patients (24\%) by PET/CT. Gastric uptake was present in 10 cases (12.6\%) and was mainly described as diffuse at the gastric wall. Intestinal accumulation were $9(11.4 \%)$ and were focal at the level of right iliac fossa for 2 and diffuse for the remainings. Colorectal accumulation was presented in $3(3.8 \%)$ cases.

The false-negative rate of 18F-FDG PET/CT in upper GI tract (EGD with biopsy) was observed in $20.5 \%$ of cases, while positive upper GI tract lesions in $12.5 \%$ patients were false-positive. The Se of 18F-FDG $\mathrm{PET} / \mathrm{CT}$ in the upper $\mathrm{Gl}$ tract in comparison to gastric biopsy (n.39, prevalence 33\%) was therefore $61.90 \%$ (38.44\% to $81.89 \% 95 \mathrm{Cl})$, while Sp was $83.87 \%(66.27 \%$ to $94.55 \% 95 \mathrm{Cl})$. Ac, PPV and NPV were $76.62 \%$ (62.83\% to $87.24 \% 95 \mathrm{Cl}), 65.40 \%(44.20 \%$ to $81.86 \% 95 \mathrm{Cl})$ and $81.72 \%$ ( $71.72 \%$ to $88.74 \% 95 \mathrm{Cl})$, respectively. Most false-positive were described at biopsy as gastritis and nonspecific lesions. Se, Sp, Ac, PPV and NPV of PET/CT in comparison to EGD (n.43, prevalence $35 \%$ ) were $60 \%$ (38.67\% to $78.87 \%$ $95 \mathrm{Cl}), 84.85 \%$ (68.10\% to $94.89 \% 95 \% \mathrm{Cl}), 76.15 \%(63.15 \%$ to $86.36 \% 95 \mathrm{Cl}), 68.07 \%(47.22 \%$ to $83.56 \%$ $95 \mathrm{Cl}), 79.75 \%(70.47 \%$ to $86.67 \% 95 \mathrm{Cl})$, respectively.

Comparing 18F-FDG PET/CT and colorectal biopsy (n.25, prevalence 44\%), we observed a false-negative rate of $20 \%$ and a false-positive rate of $4 \%$. Se was $68.75 \%$ ( $41.34 \%$ to $88.98 \% 95 \mathrm{Cl})$, Sp $93.33 \%(68.05 \%$ to $99.83 \% 95 \mathrm{Cl})$. Ac, PPV and NPV were $82.52 \%$ ( $64.68 \%$ to $93.73 \% 95 \mathrm{Cl}), 89.01 \%(54.24 \%$ to $98.23 \%$ $95 \mathrm{Cl})$ and $79.17 \%(64.48 \%$ to $88.84 \% 95 \mathrm{Cl})$, respectively. Se, Sp, Ac, PPV, NPV of PET/CT in comparison to colonoscopy (n.27, prevalence $33 \%$ ) were $69.23 \%$ (38.57\% to $90.91 \% 95 \mathrm{Cl}), 94.74 \%$ (73.97\% to $99.87 \%$ $95 \mathrm{Cl}), 86.32 \%(69.55 \%$ to $95.84 \% 95 \mathrm{Cl}), 86.63 \%$ ( $48.17 \%$ to $97.83 \% 95 \mathrm{Cl}), 86.21 \%$ (73.31\% to $93.43 \%$ $95 \mathrm{Cl})$, respectively. We could mention a bias in this group, because, in the case of 18F-FDG PET/CT negativity in lower GI tract, not all patients had proceeded with colonoscopy.

Using the lesion-by-lesion analysis by Cohen's k test, 18F-FDG PET/CT and gastric biopsy showed a $66.6 \%$ of agreement, $\mathrm{k} 0.20$ (fair agreement). Cohen's $k$ test for $18 \mathrm{~F}-\mathrm{FDG}$ PET/CT and EGD was 0.17 (65\%, 
slight agreement). In the lower GI tract, k was 0.49 (76\%, moderate agreement) for 18F-FDG PET/CT and colorectal biopsy and 0.54 (81.48\%, moderate agreement) for 18F-FDG PET/CT and colonoscopy.

All presented results are summarized in Table 2 and 3.

At the end of treatment, 47 patients (59.5\%) underwent 18F-FDG PET/CT to evaluate the response. Among these patients, only one presented a gastric accumulation, but gastric biopsy was negative. In the same patient, colonoscopy and biopsy were positive and this was the only patients with persistent colorectal disease after treatment. We did not found any final positive gastric biopsy.

We analyzed the subset of patients with initial stage disease (I-II) by PET/CT (n. 8, 10.1\%), but it was not possible to make any conclusion about a stage modification with the endoscopy execution, because of the sample little size.

\section{Discussion}

Accurate staging and evaluation of response to treatment have a broad influence on the management of MCL patients. In the last decade, the implementation of clinical decisions, taking into consideration $18 \mathrm{~F}-$ FDG PET/CT at various steps of disease assessment, has allowed to marked improvement of outcome $[16,7]$. Although 18F-FDG PET/CT shows high performances in FDG-avid NHL, there are some complementary and invasive exams which cannot yet be omitted. This is due to the maximum specificity for nodal lesions but less accuracy in the definition of extranodal localizations, first of all bone marrow. This is also true for the definition of GI involvement by MCL. Just one previous study analyzed the potentiality of this imaging technique, showing not exhaustive data [10].

GI involvement by MCL could occur up to $80-90 \%$ of patients, with clinical implications both on treatment and evaluation of final response to induction therapy. Despite this high prevalence, actual international guidelines do not consider mandatory for the execution of endoscopic procedures, advicing it only in a limited subset of MCL patients. In fact, they recommend EGD and colonoscopy in symptomatic patients and for they who present limited stages at 18F-FDG PET/CT, allowing in some cases to detect an advanced stage disease $[18,19]$. By this way, in the real life we are not able to know whether stomach or bowel are involved in asymptomatic patients, who could benefit of a strengthen supportive care and, to a greater extent, of a correct re-staging of disease at the end of front-line treatment. In this context, we have also to consider that not all patients are eligible for GI endoscopy, due to impaired performance status or urgency to start treatment.

Of course, it will be desirable that 18F-FDG PET/CT could overcome the use of invasive exams, but its performance in this context has to be dealt with. Even with the limit of the retrospective nature of the study and the little number of patients, we found an overall GI involvement in $24 \%$ of patients by $18 \mathrm{~F}-\mathrm{FDG}$ PET/CT (gastric 12.6\%, intestinal 11.4\%, colorectal 3.8\%). We assessed that Se and Sp of 18F-FDG $\mathrm{PET} / \mathrm{CT}$ is low for the stomach $(61.90 \%$ and $83.87 \%$, respectively), mainly for the presence of false positive due to gastritis or nonspecific lesions, with a fair concordance with the pathological findings ( $\mathrm{K}$ 
$0.20,66.6 \%$ of agreement). We, therefore, recommend the execution of the EGD and biopsy in the staging of symptomatic and asymptomatic MCL patients, if allowed by performance status, and to repeat the exam at re-evaluation when positive. For the detection of colorectal localizations, in our cohort PET/CT has demonstrated higher concordance with pathologic results ( $0.49,76 \%$ of agreement) and falsepositivity in just $4 \%$ of cases. These data suggest that colonoscopy, which is surely invasive and debilitating, could be omitted in asymptomatic patients (Table 4).

The unique study available on the topic, recently presented by Albano et al, showed a slight higher performances of PET/CT for GI involvement by MCL, with Se of $64 \%$, Sp of $91 \%$ and Ac of $85 \%$. However, these data are not splitted for the upper and lower GI tract, not providing comparable results with ours.

To our knowledge this is the first study that documents the limits of 18F-FDG PET/CT in detecting GI tract localization in MCL patients. Our study could be of practical help in the clinical management of MCL patients, allowing an integration among previous reports and guidelines. The validation of our data in larger cohorts and in prospective clinical trials could certainly allow to confirm our findins.

\section{Conclusions}

Analyzed data suggest that the performance of 18F-FDG PET/CT is not excellent in the detection of gastric lesions by MCL, and thus EGD with biopsy has yet to be considered a "golden standard" in this subset, while colonoscopy could be omitted due to a higher accuracy and specificity. Se and Sp of 18FFDG PET/CT scan is low for the stomach, with a fair concordance with the pathological findings (Table 4).

Taking into account the limit of the retrospective nature of the study, data should be confirmed on larger and prospective cohort.

\section{Declarations}

\section{Ethical Approval and Consent to participate.}

The study was aproved on 28/03/2017 by ethics committee in Oncology Institute "Giovanni Paolo II" ISTITUTO DI RICOVERO E CURA A CARATTERE SCIENTIFICO, viale Orazio Flacco, 65 - 70124, Bari, Italy.

Protocol number 619 del CE

\section{Consent for publication}

All consents are available upon request.

\section{Availability of data and material.}


The datasets used and/or analysed during the current study are available from the corresponding author on reasonable request.

\section{Competing interests.}

The authors declare that they have no competing interests

\section{Funding.}

No fundings.

\section{Authors' contributions.}

TS and CM discussed, designed, conceptualized and wrote an article. All other authors: LN, GMC, BP, LM, $S K, K F, I K, A M S, A D, G S, C F, A G$ provided databases from their centers with clinical and radiological data. $L N, G M C, B P, L M, S K, K F, I K, A M S, A D, G S, C F$, and $A G$ took part in revisions. Statistics analysis was performed by MCV. Literature review and the final revision of the article were performed by TS and CM.

\section{Acknowledgements}

Not applicable

\section{Abbreviations}

18F-FDG PET/CT fluorine-18-fluorodeoxyglucose positron emission tomography/computed tomography

Ac accuracy

ASCT autologous hematopoietic stem cell transplant

B-NHL B-cell non-Hodgkin lymphoma

BM bone marrow

CT computed tomography

EGD esophagogastroduodenoscopy

GI gastrointestinal tract

MCL mantle-cell lymphoma

MIPI MCL International Prognostic Index

NPV negative predictive value

PPV positive predictive value 
PET positron emission tomography

R-BAC500 rituximab, bendamustine, high-dose cytrabine

R-CHOP rituximab, cyclophosphamide, doxorubicin, vincristine, prednisone

R-CVP rituximab, cyclophosphamide, prednisone

R-DHAOx rituximab, dexamethasone, high-dose ara-C, oxaliplatin

R-DHAP rituximab, dexamethasone, high-dose ara-C, cisplatin

Se sensitivity

Sp specificity

\section{References}

1 - Swerdlow SH, Campo E, Pileri SA, et al. The 2016 revision of the World Health Organization classification of lymphoid neoplasms. Blood. 2016; 127: 2375- 2390.

2 - Hoster E, Dreyling M, Klapper W, Gisselbrecht C, van Hoof A, Kluin-Nelemans HC, Pfreundschuh M, Reiser M, Metzner B, Einsele H, Peter N, Jung W, Wörmann B, Ludwig WD, Dührsen U, Eimermacher H, Wandt H, Hasford J, Hiddemann W, Unterhalt M; German Low Grade Lymphoma Study Group (GLSG); European Mantle Cell Lymphoma Network. A new prognostic index (MIPI) for patients with advancedstage mantle cell lymphoma. Blood. 2008 Jan 15;111(2):558-65.

3 - Hoster E, Klapper W, Hermine O, Kluin-Nelemans HC, Walewski J, van Hoof A, Trneny M, Geisler CH, Di Raimondo F, Szymczyk M, Stilgenbauer S, Thieblemont C, Hallek M, Forstpointner R, Pott C, Ribrag V, Doorduijn J, Hiddemann W, Dreyling MH, Unterhalt M. Confirmation of the mantle-cell lymphoma International Prognostic Index in randomized trials of the European Mantle-Cell Lymphoma Network. J Clin Oncol. 2014; 32(13):1338-46.

4 - Klener P. Advances in Molecular Biology and Targeted Therapy of Mantle Cell Lymphoma. Int J Mol Sci. 2019;20(18):4417.

5 - Sarkozy C, Terré C, Jardin F, Radford I, Roche-Lestienne C, Penther D, Bastard C, Rigaudeau S, Pilorge S, Morschhauser F, Bouscary D, Delarue R, Farhat H, Rousselot P, Hermine O, Tilly H, Chevret S, Castaigne S. Complex karyotype in mantle cell lymphoma is a strong prognostic factor for the time to treatment and overall survival, independent of the MCL international prognostic index. Genes Chromosomes Cancer. 2014 Jan;53(1):106-16.

6 - Fernandez V, Salamero O, Espinet B, et al. Genomic and gene expression profiling defines indolent forms of mantle cell lymphoma. Cancer Res 2010;70:1408-18. 
7 - Barrington SF, Mikhaeel NG, Kostakoglu L, Meignan M, Hutchings M, Müeller SP, Schwartz LH, Zucca E, Fisher RI, Trotman J, Hoekstra OS, Hicks RJ, O'Doherty MJ, Hustinx R, Biggi A, Cheson BD. Role of imaging in the staging and response assessment of lymphoma: consensus of the International Conference on Malignant Lymphomas Imaging Working Group. J Clin Oncol. 2014 Sep 20;32(27):304858 .

8 - Cheson BD, Fisher RI, Barrington SF, Cavalli F, Schwartz LH, Zucca E, Lister TA. Recommendations for initial evaluation, staging, and response assessment of Hodgkin and non-Hodgkin lymphoma: the Lugano classification. J Clin Oncol. 2014 Sep 20;32(27):3059-68.

9- Gill S, Wolf M, Prince HM, Januszewicz H, Ritchie D, Hicks RJ, Seymour JF. [18F]fluorodeoxyglucose positron emission tomography scanning for staging, response assessment, and disease surveillance in patients with mantle cell lymphoma. Clin Lymphoma Myeloma. 2008 Jun;8(3):159-65.

10 - Albano D, Ferro P, Bosio G, Fallanca F, Re A, Tucci A, Maria Ferreri AJ, Angelillo P, Gianolli L, Giubbini R, Bertagna F. Diagnostic and Clinical Impact of Staging 18F-FDG PET/CT in Mantle-Cell Lymphoma: A Two-Center Experience. Clin Lymphoma Myeloma Leuk. 2019 Aug;19(8):e457-e464.

11- Romaguera JE1, Medeiros LJ, Hagemeister FB, Fayad LE, Rodriguez MA, Pro B, Younes A, McLaughlin P, Goy A, Sarris AH, Dang NH, Samaniego F, Brown HM, Gagneja HK, Cabanillas F. Frequency of gastrointestinal involvement and its clinical significance in mantle cell lymphoma. Cancer. 2003 Feb 1;97(3):586-91.

12 - Salar A, Juanpere N, Bellosillo B, Domingo-Domenech E, Espinet B, Seoane A, Romagosa V, GonzalezBarca E, Panades A, Pedro C, Nieto M, Abella E, Solé F, Ariza A, Fernández-Sevilla A, Besses C, Serrano S. Gastrointestinal involvement in mantle cell lymphoma: a prospective clinic, endoscopic, and pathologic study. Am J Surg Pathol. 2006 Oct;30(10):1274-80.

13 - Iwamuro M, Okada H, Kawahara Y, Shinagawa K, Morito T, Yoshino T, Yamamoto K. Endoscopic features and prognoses of mantle cell lymphoma with gastrointestinal involvement. World $\mathrm{J}$ Gastroenterol. 2010 Oct 7;16(37):4661-9.

14 - Maggialetti N, Ferrari C, Minoia C, Asabella AN, Ficco M, Loseto G, De Tullio G, de Fazio V, Calabrese A, Guarini A, Rubini G, Brunese L. Role of WB-MR/DWIBS compared to (18)F-FDG PET/CT in the therapy response assessment of lymphoma. Radiol Med. 2016 Feb;121(2):132-43.

15 - Landis JR, Koch G.G. The measurement of observer agreement for categorical data. Biometrics, 33, 159-174 (1977).

16 - Gallamini A, Zwarthoed C, Borra A. Positron Emission Tomography (PET) in Oncology. Cancers (Basel). 2014;6(4):1821-1889. 
17 - Juweid ME, Stroobants S, Hoekstra OS, Mottaghy FM, Dietlein M, Guermazi A et al (2007) Imaging Subcommittee of International Harmonization Project in Lymphoma. Use of positron emission tomography for response assessment of lymphoma: consensus of the Imaging Subcommittee of International Harmonization Project in Lymphoma. J Clin Oncol 25(5):571-578.

18 - Zelenetz AD, Gordon LI, Abramson JS, Advani RH, Bartlett NL, Caimi PF, Chang JE, Chavez JC, Christian B, Fayad LE, Glenn MJ, Habermann TM, Lee Harris N et al. NCCN guidelines version 5.2019 Bcell lymphomas, September 23, 2019.

19 - Dreyling M, Campo E, Hermine O, Jerkeman M, Le Gouill S, Rule S, Shpilberg O, Walewski J, Ladetto M; ESMO Guidelines Committee. Newly diagnosed and relapsed mantle cell lymphoma: ESMO Clinical Practice Guidelines for diagnosis, treatment and follow-up. Ann Oncol. 2017 Jul 1;28(suppl_4):iv62-iv71.

\section{Tables}

Table 1. Patients' baseline characteristics 


\begin{tabular}{|c|c|c|}
\hline Patients' characteristics & $\mathrm{N}=79$ & $\%(100)$ \\
\hline Age at evaluation, years (mean, range) & $66.8(27-83)$ & \\
\hline $\begin{array}{l}\text { Male } \\
\text { Female }\end{array}$ & $\begin{array}{l}52 \\
27\end{array}$ & $\begin{array}{l}65.8 \\
34.2\end{array}$ \\
\hline $\begin{array}{l}\text { Stage } \\
\text { I/II } \\
\text { III/IV }\end{array}$ & $\begin{array}{l}79 \\
8 \\
71\end{array}$ & $\begin{array}{l}100 \\
10.1 \\
89.9\end{array}$ \\
\hline $\begin{array}{l}\text { B-symptoms } \\
\text { Present } \\
\text { Absent }\end{array}$ & $\begin{array}{l}79 \\
8 \\
71\end{array}$ & $\begin{array}{l}100 \\
10.1 \\
89.9\end{array}$ \\
\hline $\begin{array}{l}\text { Bone marrow infiltration } \\
\text { Yes } \\
\text { No }\end{array}$ & $\begin{array}{l}77 \\
58 \\
19\end{array}$ & $\begin{array}{l}97.5 \\
75.3 \\
24.7\end{array}$ \\
\hline $\begin{array}{l}\text { Extra-nodal involvement (other than bone marrow and GI) } \\
\text { Yes } \\
\text { No }\end{array}$ & $\begin{array}{l}79 \\
9 \\
70\end{array}$ & $\begin{array}{l}100 \\
11.4 \\
88.6\end{array}$ \\
\hline $\begin{array}{l}\text { Site of extra-nodal involvement (other than bone marrow and GI) by PET/CT } \\
\quad \text { orbit } \\
\text { liver } \\
\text { rinopharynx } \\
\text { soft palate } \\
\text { lung } \\
\text { pleura } \\
\text { adrenal gland }\end{array}$ & $\begin{array}{l}9 \\
2 \\
2 \\
1 \\
1 \\
1 \\
1 \\
1\end{array}$ & $\begin{array}{l}11.4 \\
22.2 \\
22.2 \\
11.1 \\
11.1 \\
11.1 \\
11.1 \\
11.1\end{array}$ \\
\hline $\begin{array}{l}\text { MIPI score } \\
\text { Low risk }(0-5.7) \\
\text { Intermediate risk }(5.7-6.2) \\
\text { High risk }(>6.2) \\
\end{array}$ & $\begin{array}{l}79 \\
20 \\
28 \\
31\end{array}$ & $\begin{array}{l}100 \\
25.3 \\
35.5 \\
39.2 \\
\end{array}$ \\
\hline $\begin{array}{l}\text { Simplified MIPI score } \\
\text { Low risk }(0-3) \\
\text { Intermediate risk (4-5) } \\
\text { High risk }(>6) \\
\end{array}$ & $\begin{array}{l}79 \\
19 \\
40 \\
20\end{array}$ & $\begin{array}{l}100 \\
24.1 \\
50.6 \\
25.3 \\
\end{array}$ \\
\hline $\begin{array}{l}\text { Ki } 67 \% \\
\quad=<30 \% \\
>30 \%\end{array}$ & $\begin{array}{l}48 \\
25 \\
23\end{array}$ & $\begin{array}{l}60.7 \\
52 \\
48\end{array}$ \\
\hline $\begin{array}{l}\text { Blastoid variant } \\
\text { Yes } \\
\text { No }\end{array}$ & $\begin{array}{l}79 \\
5 \\
74\end{array}$ & $\begin{array}{l}100 \\
6.3 \\
93.7\end{array}$ \\
\hline $\begin{array}{l}\text { Type of induction chemotherapy } \\
\text { R-CHOP/R-DHAP or R-DHAOx } \\
\text { R-CHOP/ HD-AraC } \\
\text { R-CHOP } \\
\text { R-BAC500/ HD-AraC } \\
\text { R-BAC500 } \\
\text { R-B } \\
\text { R-CVP } \\
\text { Watch and wait } \\
\text { Autologous stem cell transplant } \\
\text { Rituximab maintenance } \\
\text { Lenalidomide maintenance (clinical trial) }\end{array}$ & $\begin{array}{l}78 \\
16 \\
3 \\
16 \\
4 \\
10 \\
22 \\
3 \\
4 \\
21 \\
11 \\
3\end{array}$ & $\begin{array}{l}98.7 \\
20.6 \\
3.8 \\
20.6 \\
5.1 \\
12.8 \\
28.2 \\
3.8 \\
5.1 \\
26.9 \\
14.1 \\
3.8\end{array}$ \\
\hline $\begin{array}{l}\text { Response to inducion chemotherapy } \\
\text { CR } \\
\text { PR } \\
\text { SD } \\
\text { PD }\end{array}$ & $\begin{array}{l}62 \\
51 \\
8 \\
0 \\
3 \\
\end{array}$ & $\begin{array}{l}78.5 \\
82.2 \\
12.0 \\
0 \\
4.9 \\
\end{array}$ \\
\hline $\begin{array}{l}\text { Disease relapse/progression } \\
\text { Yes }\end{array}$ & $\begin{array}{l}65 \\
34\end{array}$ & $\begin{array}{l}82.3 \\
52.3\end{array}$ \\
\hline
\end{tabular}


GI, gastrointestinal; MIPI, Mantle Cell Lymphoma International Prognostic Index; R-CHOP, rituximab, cyclophosphamide, doxorubicin, vincristine, prednisone; R-DHAP, rituximab, dexamethasone, high-dose ara-C, cisplatin; R-DHAOx, rituximab, dexamethasone, high-dose ara-C, oxaliplatin; R-BAC, rituximab, bendamustine, ara-C; R-B, rituximab, bendamustine; R-CVP, rituximab, cyclophosphamide, prednisone; CR, complete response; $\mathrm{PR}$, partial response; SD, stable disease; $\mathrm{PD}$, progressive disease

Table 2. Comparison between patients with positive and negative GI endoscopy, biopsy and 18F-FDG PET/CT

\begin{tabular}{l|c|c|c|c}
\hline \multirow{2}{*}{ 18F-FDG PET/CT results } & \multicolumn{2}{|c|}{ EGD } & \multicolumn{2}{c}{ Colonoscopy } \\
\cline { 2 - 5 } & Positive & Negative & Positive & Negative \\
\hline \multirow{2}{*}{ Positive } & 15 & 5 & & 9 \\
Negative & 10 & 28 & 4 & 18 \\
\hline 18F-FDG PET/CT results & \multicolumn{2}{|c|}{ Gastric biopsy } & Colorectal biopsy \\
\cline { 2 - 5 } & Positive & Negative & Positive & Negative \\
\hline Positive & 13 & 5 & 11 & 1 \\
Negative & 8 & 26 & 5 & 14 \\
\hline
\end{tabular}

18F-FDG PET/CT, fluorine-18-fluorodeoxyglucose positron emission tomography (PET)/computed tomography (CT); EGD, esophagogastroduodenoscopy

Table 3. Performance of 18F-FDG PET/CT in detecting GI involvement by MCL, compared with endoscopy and biopsy 


\begin{tabular}{|c|c|c|c|c|}
\hline \multirow[t]{2}{*}{$\begin{array}{c}\text { 18F-FDG PET/CT } \\
\text { (n. } 79,100 \%)\end{array}$} & \multicolumn{2}{|c|}{ Gastric involvement } & \multicolumn{2}{|c|}{ Colorectal involvement } \\
\hline & $\begin{array}{c}\text { EGD } \\
\text { (n. 43, prevalence } \\
35 \% \text { ) }\end{array}$ & $\begin{array}{c}\text { Gastric biopsy } \\
\text { (n. 39, prevalence 33\%) }\end{array}$ & $\begin{array}{c}\text { Colonoscopy } \\
\text { (n. 27, prevalence 33\%) }\end{array}$ & $\begin{array}{c}\text { Colorectal biopsy } \\
\text { (n. } 25 \text {, prevalence } 44 \% \text { ) }\end{array}$ \\
\hline Se $(95 \% C I)$ & $60.00 \%(38.67-78.87 \%)$ & $61.90 \%(38.44-81.89 \%)$ & $69.23 \%$ (38.57-90.91\%) & $68.75 \%(41.34-88.98 \%)$ \\
\hline $\mathrm{Sp}(95 \% \mathrm{CI})$ & $84.85 \%$ (68.10-94.89\%) & 83.87\% (66.27-94.55\%) & $94.74 \%$ (73.97-99,87\%) & $93.33 \%(68.05-99.83 \%)$ \\
\hline PPV (95\%CI) & $68.07 \%(47.22-83.56 \%)$ & $65.40 \%$ (44.20-81.86\%) & $86.63 \%$ (48.17-97.83\%) & $89.01 \%$ (54.24-98.23\%) \\
\hline NPV (95\%CI) & $79.75 \%$ (70.47-86.67\%) & $81.72 \%$ (71.72-88.74\%) & $86.21 \%$ (73.31-93.43\%) & $79.17 \%$ (64.48-88.84\%) \\
\hline Accuracy $(95 \% \mathrm{CI})$ & $76.15 \%(63.15-86.36 \%)$ & $76.62 \%$ (62.83-87.24\%) & $86.32 \%$ (69.55-95.84\%) & $82.52 \%(64.68-93.73 \%)$ \\
\hline $\begin{array}{l}\text { Cohen's k test } \\
\qquad(95 \% \mathrm{CI})\end{array}$ & 0.17 , agreement $65 \%$ & 0.20 , agreement $66.6 \%$ & 0.54 , agreement $81.48 \%$ & 0.49 , agreement $76 \%$ \\
\hline
\end{tabular}

18F-FDG PET/CT, fluorine-18-fluorodeoxyglucose positron emission tomography (PET)/computed tomography (CT); EGD, esophagogastroduodenoscopy; PPV, positive predictive value; Se, sensitivity; Sp, specificity; NPV, negative predictive value.

PPV, NPV and accuracy are dependent on prevalence of the event. Cohen's k test (95\%CI) "slight agreement" - 0.01-0.20; "fair agreement" - 0.21-0.40; "moderate agreement" - 0.41-0.60; "substantial agreement" - 0.61-0.80; "almost perfect or perfect agreement" - 0.81-1.00

\section{Table 4. Summary on the role of PET/CT in the detection of GI involvement by MCL}

\section{Background}

- GI tract involvements by MCL is mostly asymptomatic and often affects many GI segments

. GI involvement is more frequent than expected; it is, reported in the 15-80\% of MCL by different studies $[11,12]$

. By ESMO and NCCN guidelines, GI endoscopy is recommended for symptomatic patients and for patients who present a early stage disease at 18F-FDG PET/CT , allowing in some cases to detect a advanced stage $[18,19]$ . A limited number of published studies demonstrated a low sensitivity of 18F-FDG PET/CT for GI [10]

\section{Summary from the present study}

. Se and Sp of 18F-FDG PET/CT scan is low for the stomach, with a fair concordance with the pathological findings . If allowed by performance status, we advice the execution of the EGD and biopsy in the staging of symptomatic and asymptomatic MCL patients and to repeat the exam at re-staging when positive

. In the detection of colorectal localizations, in our cohort 18F-FDG PET/CT has demonstrated higher concordance with pathologic results . The data suggest that colonoscopy could be omitted in asymptomatic patients

PET/CT, Positron Emission Tomography/Computed Tomography; GI, gastrointestinal; MCL, Mantle-Cell Lymphoma; ESMO, European Society for Medical Oncology; NCCN, National Comprehensive Cancer Network 


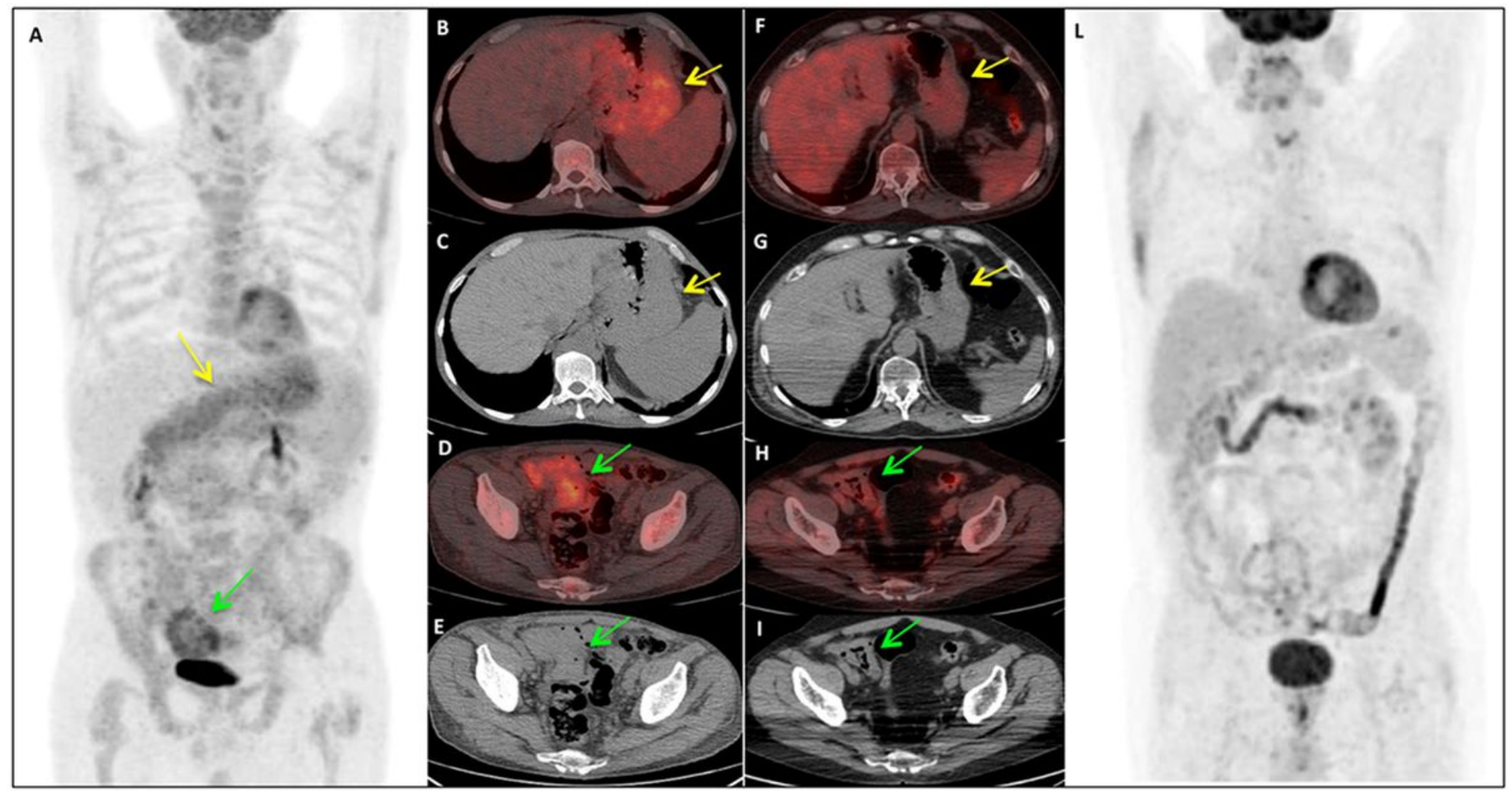

Figure 1

(A-L) 18F-FDG PET/CT assessment in a patient affected by MCL treated with RCHOP/RDHAP. (A-E) Baseline MIP (A), axial fused (B, D) and CT images (C, E): PET/CT demonstrated pathological 18FDG uptake (SUV max 4.9) in the whole stomach wall (B, yellow arrow), which appear thickened the reference $C T$ images (C, yellow arrow), as well as in the intestinal walls (SUV max 5.2) in the right pelvic area $(D$, green arrow), which appear conglomerate (E, green arrow). (F-L) Post-therapy evaluation MIP (L), axial fused $(F, H)$ and $C T$ images $(G, I)$ : PET/CT demonstrated complete disappearance of 18F-FDG uptake both in stomach and intestinal walls $(F, H)$, which returned to be of normal thickening also at CT images $(G, I)$. 